\title{
Upgrading of Coffee Biocrude Oil Produced by Pyrolysis of Spent Coffee Grounds: Behavior of Fatty Acids in Supercritical Ethanol Reaction and Catalytic Cracking
}

\author{
Ji-Yeon Park, Md Amirul Alam Kanak and In-Gu Lee *(D)
}

check for

updates

Citation: Park, J.-Y.; Kanak, M.A.A; Lee, I.-G. Upgrading of Coffee Biocrude Oil Produced by Pyrolysis of Spent Coffee Grounds: Behavior of Fatty Acids in Supercritical Ethanol Reaction and Catalytic Cracking. Processes 2021, 9, 835. https:// doi.org/10.3390/pr9050835

Academic Editor: Shahabaldin Rezania

Received: 22 April 2021

Accepted: 6 May 2021

Published: 10 May 2021

Publisher's Note: MDPI stays neutral with regard to jurisdictional claims in published maps and institutional affiliations.

Copyright: (c) 2021 by the authors. Licensee MDPI, Basel, Switzerland. This article is an open access article distributed under the terms and conditions of the Creative Commons Attribution (CC BY) license (https:/ / creativecommons.org/licenses/by/ $4.0 /)$.
Energy Resources Upcycling Research Laboratory, Korea Institute of Energy Research, 152 Gajeong-ro, Yuseong-gu, Daejeon 34129, Korea; yearn@kier.re.kr (J.-Y.P.); amirulkanak@kier.re.kr (M.A.A.K.)

* Correspondence: samwe04@kier.re.kr; Tel.: +82-42-860-3559

\begin{abstract}
Spent coffee grounds contain lipids (fatty acids) in addition to cellulose, hemicellulose, and lignin. The reaction process for upgrading biocrude oil produced from spent coffee grounds is different from that followed for upgrading biomass pyrolysis oil, such as processes that utilize sawdust. The feasibility of upgrading coffee biocrude oil through a supercritical ethanol reaction with plastic pyrolysis oil and through catalytic cracking for the improvement of the undesirable properties of biocrude oil, caused by the presence of oxygenated compounds, was evaluated. The initial oxygen content of the coffee biocrude oil was $16.9 \mathrm{wt} \%$. The oil comprised a total content of $40.9 \%$ fatty acids, as found by analyzing the GC-MS peak area. After the supercritical ethanol reaction at $340{ }^{\circ} \mathrm{C}$, the oxygen content was decreased to $9.9 \mathrm{wt} \%$. When the $\mathrm{MgNiMo} / \mathrm{AC}$ catalyst was applied to the supercritical reaction, the oxygen content was further decreased to $8.5 \mathrm{wt} \%$. The esterification of the fatty acids in the biocrude oil with ethanol converted them to esters. After the supercritical reaction of coffee biocrude oil with plastic pyrolysis oil $(1: 2(w / w))$, the oxygen content was $6.4 \mathrm{wt} \%$. After the catalytic cracking of the biocrude oil by Ni/MCM- 41 at $400{ }^{\circ} \mathrm{C}$, the fatty acids were converted to hydrocarbons, $\mathrm{C} 9$ to $\mathrm{C} 21$, and the oxygen content decreased to a final value of $2.8 \mathrm{wt} \%$.
\end{abstract}

Keywords: spent coffee grounds; waste plastic; pyrolysis oil; supercritical ethanol; catalytic cracking; oxygen content

\section{Introduction}

Due to issues such as the depletion of fossil fuels, global warming, and environmental pollution, interest in renewable energy has increased. Biomass is a sustainable energy source that reduces carbon dioxide emissions by absorbing carbon dioxide for photosynthesis. Given that lignocellulosic biomass is the most abundant non-food biomass in the world, the production of biocrude oil through the fast pyrolysis of lignocellulosic biomass is a particularly attractive process [1-3]. Biocrude oil can be applied to furnaces or boilers, through direct combustion, and to engines and turbines by upgrading to high-quality hydrocarbon fuels, and to high-value-added chemicals [4]. Although biocrude oil is one of the most promising clean and renewable energy resources as a replacement for fossil fuel, it has undesirable properties, such as high moisture content, high oxygen content, high acid value, low heating value, and high reactivity, which is caused by the presence of oxygenated and unsaturated compounds [5,6]. Aldehydes and phenolic species tend to easily polymerize and increase oil viscosity. The high moisture content and oxygenated compounds result in low heating values and immiscibility with conventional fossil fuels. These highly acidic compounds result in thermally unstable and highly corrosive oil [7].

Upgrading biocrude oil to oil with lower oxygen and acidic species contents is required in order to improve its storage stability and, thus, suitability as a viable fossil fuel replacement. Biocrude oil upgrading techniques, such as emulsification, catalytic cracking, hydrodeoxygenation, and catalytic deoxygenation, have been reported [8,9]. The catalytic 
cracking of biocrude oil efficiently converts hydrocarbons by removing oxygen in the presence of the zeolite catalyst [8]. The resultant hydrocarbon products have the potential to be used as platform chemicals for the production of fuels, lubricants, and other valuable petrochemicals. Catalytic deoxygenation also upgrades biocrude oil by reducing the oxygen content in several chemical reactions, including decarbonylation, decarboxylation, and hydrodeoxygenation. In fact, relatively inexpensive transition metal catalysts, such as nickel, have shown excellent catalytic activity that is comparable to novel metal catalytic activity for hydrodeoxygenation [10].

Another biocrude oil upgrade route is through organic acid removal by esterification with alcohol and an acid catalyst. Decreased acidity and viscosity can enhance the quality of biocrude oil. Esterification using supercritical fluids, such as water, methanol or ethanol, for the removal of organic acids in biocrude oil with or without catalysts has been intensively researched, due to the supercritical fluid system's unique properties, which include faster rates of mass and heat transfer, liquid-like density and dissolving power, and gas-like diffusivity and viscosity [10-13]. In supercritical ethanol, ethanol reacts with carboxylic acids in biocrude oil and produces the corresponding esters by esterification, even without catalysts. Supercritical ethanol acts as an effective reactant medium by reducing the viscosity of biocrude oil. Ethanol can also produce hydroxyl and hydrogen radicals in reactions with biocrude oil in the supercritical state [14,15].

Among lignocellulosic biomass, coffee has a huge potential for biomass feedstock, simply because it is one of the most popular beverages worldwide. Typically, most coffee grounds are disposed of as waste, while only a small amount is employed as compost or for use in deodorants. Because the rate of coffee consumption is continuously increasing, spent coffee grounds could be a promising biomass resource for production of biocrude oil [4]. However, spent coffee grounds contain additional lipids besides cellulose, hemicellulose, and lignin (the major components of lignocellulosic biomass); the reaction process for upgrading biocrude oil that is produced from spent coffee grounds is predicted to be very different from that followed for upgrading pyrolysis oil from lignocellulosic biomass, such as sawdust $[16,17]$. Lipids can be extracted from spend coffee grounds using organic solvents and subsequently converted to biodiesel by transesterification [18,19]. Coffee biocrude oil has been found to contain highly acidic substances originating from lipids, the major compounds of which are palmitic acid, oleic acid, and stearic acid [16]. The catalytic cracking of fatty acids in coffee biocrude oil for lowering the oxygen and acid contents can be utilized to improve the oil's properties. However, studies on upgrading biocrude oil produced from spent coffee grounds by fast pyrolysis are rare.

Meanwhile, waste plastic is one of the most common wastes in the world, its global production has been steadily increasing for more than 50 years. The short-lived use of plastic products causes a drastic accumulation of waste plastic worldwide, and waste plastic accounts for 10-12\% of municipal solid waste [20]. Appropriate management of waste plastic is now a significant public concern, especially given the dire environmental risk and the necessity of meeting increasingly stringent waste-separation regulations. The plastic waste to energy conversion process via pyrolysis, for example, has demonstrated the potential to produce high-value-added products, such as chemicals and fuels [20]. Plastic pyrolysis oil's abundance of aliphatic and aromatic hydrocarbons is expected to improve the low-grade properties of oxygen-rich biocrude oil when combined with the latter [21].

In the present study, coffee biocrude oil produced by the pyrolysis of spent coffee grounds was upgraded with three methods: (i) a supercritical ethanol reaction with and without catalyst, (ii) a supercritical ethanol reaction with plastic pyrolysis oil, and (iii) catalytic cracking with Ni/MCM-41. The changes in the properties of coffee biocrude oil, including the lipids (fatty acids), through each upgrading method, were compared for their reduced oxygen and acid contents and increased heating values. 


\section{Materials and Methods}

\subsection{Materials}

Coffee biocrude oil, prepared through the fast pyrolysis of spent coffee grounds, was provided by the Korea Institute of Machinery and Materials [4]. Prior to the experimentation, the oil was evaporated at $150{ }^{\circ} \mathrm{C}$ to remove water and volatile compounds. Spent coffee grounds with a moisture content of $57.8 \%$ were dried in an oven overnight at $105{ }^{\circ} \mathrm{C}$ for analysis of their fatty acid contents. Concurrently, plastic pyrolysis oil was prepared from mixed-waste plastics by the Korea Institute of Energy Research [22]. Ethanol (99.9\%) for use as a supercritical solvent was supplied by OCI Company Ltd. Nickel (II) nitrate hexahydrate $\left(\mathrm{Ni}\left(\mathrm{NO}_{3}\right)_{2} \cdot 6 \mathrm{H}_{2} \mathrm{O}, 99.999 \%\right)$, ammonium molybdate tetrahydrate $\left(\left(\mathrm{NH}_{4}\right)_{6} \mathrm{Mo}_{7} \mathrm{O}_{24} \cdot 5 \mathrm{H}_{2} \mathrm{O}, 81.0-83.0 \%\right)$, and magnesium nitrate hexahydrate $\left(\mathrm{Mg}\left(\mathrm{NO}_{3}\right)_{2} \cdot 6 \mathrm{H}_{2} \mathrm{O}\right.$, 99\%) were purchased from Sigma-Aldrich. Activated charcoal (AC) (BET surface area: $688 \mathrm{~m}^{2} / \mathrm{g}$ ) was also supplied by Sigma-Aldrich. The AC was washed several times with distilled water to remove contaminants; after cleaning, it was dried and sieved to between 0.50 and $0.85 \mathrm{~mm}$. MCM-41 (BET surface area: $>800 \mathrm{~m}^{2} / \mathrm{g}$ ) was supplied by ACS Material.

\subsection{Preparation and Characterization of Catalysts}

Preparatory to the supercritical reaction, AC-supported catalysts were prepared by an incipient wetness impregnation method, which involved $25 \mathrm{wt} \% \mathrm{Ni}, 10 \mathrm{wt} \% \mathrm{Mo}$ and $2 \mathrm{wt} \% \mathrm{Mg}$ being impregnated consecutively on AC. The AC-supported catalysts were dried at $100{ }^{\circ} \mathrm{C}$ for $12 \mathrm{~h}$, calcined at $500{ }^{\circ} \mathrm{C}$ for $3 \mathrm{~h}$ in a $\mathrm{N}_{2}$ flow of $100 \mathrm{~mL} / \mathrm{min}$, and reduced at $400{ }^{\circ} \mathrm{C}$ for $8 \mathrm{~h}$ in a $\mathrm{H}_{2}$ flow of $100 \mathrm{~mL} / \mathrm{min}$ [23]. For catalytic cracking, MCM-41-supported catalysts also were prepared by the incipient wetness impregnation method, $25 \mathrm{wt} \% \mathrm{Ni}$ being impregnated on MCM-41. The MCM-41-supported catalysts were dried at $100{ }^{\circ} \mathrm{C}$ for $12 \mathrm{~h}$, calcined at $500^{\circ} \mathrm{C}$ for $3 \mathrm{~h}$ in a $\mathrm{N}_{2}$ flow of $100 \mathrm{~mL} / \mathrm{min}$, and reduced at $400^{\circ} \mathrm{C}$ for $8 \mathrm{~h}$ in a $\mathrm{H}_{2}$ flow of $100 \mathrm{~mL} / \mathrm{min}$. The BET-specific surface area, pore volume, and pore diameter of the prepared catalysts were determined by $\mathrm{N}_{2}$ adsorption/desorption isotherms at $-196{ }^{\circ} \mathrm{C}$ in ASAP 2420 (Micromeritics Ltd). The specific surface was calculated using the BET equation, and the pore size distributions were analyzed by the BJH method.

\subsection{Supercritical Ethanol Reaction and Catalytic Cracking Procedures}

To perform a supercritical reaction, an autoclave reactor of $200 \mathrm{~mL}$ capacity was used. The reactor was heated with an electric heating system, and the temperature was measured with a thermocouple. A total amount of $100 \mathrm{~g}$ biocrude oil/ethanol mixture was fed into the reactor. The ratio of biocrude oil to ethanol was 2:8 $(w / w)$. First, to enhance the efficiency of deoxygenation, the catalysts $\mathrm{AC}$ and $\mathrm{MgNiMo} / \mathrm{AC}$ were used with $4 \mathrm{wt} \%$ mixture. Secondly, to reduce the oxygen content, 10, 20, and $40 \mathrm{~g}$ of plastic pyrolysis oils were additionally added to $100 \mathrm{~g}$ biocrude oil/ethanol mixture. The weight ratios of coffee biocrude oil to plastic pyrolysis oil were 1:0.5, 1:1, and 1:2, respectively. In a blending experiment with plastic pyrolysis oil, there was no need for a catalyst. After sealing, the reactor was purged with nitrogen gas to remove the air in the reactor. The purging process was repeated three times, and then the reactor was pressurized, with $\mathrm{N}_{2}$ to 30 bar as an initial pressure. The reaction was performed at $340{ }^{\circ} \mathrm{C}$, the mixture being stirred at a rate of $500 \mathrm{rpm}$ for $2 \mathrm{~h}$ and then cooled to room temperature by water circulation. All of the gas, liquid, and solid products were collected from the reactor for analysis. The gas product sample was first collected with a tedlar gas-tight bag at room temperature for compositional analysis and then the remaining gas was vented outside. The reactor was opened by removing its head cover, and all the products and catalyst present in the reactor were collected. The reactor was rinsed with acetone if necessary. The collected mixture was first filtered using $1.2 \mu \mathrm{m}$ glass fiber filter papers to separate the liquid and the solid phases. The solid phase, including the solid product and catalyst, was dried at $105{ }^{\circ} \mathrm{C}$ for $12 \mathrm{~h}$, and the dried mass was measured to determine the solid product yield by deducting the weight of the catalyst used. Vacuum evaporation $\left(60^{\circ} \mathrm{C}, 1 \mathrm{~h}\right)$ and consecutive vacuum dry $\left(50^{\circ} \mathrm{C}, 5 \mathrm{~h}\right)$ were conducted to remove any reaction medium and washing solvent, 
such as ethanol and acetone present in the collected liquid phase. The yields of liquid, solid and gas products were calculated according to the following formula:

Liquid product yield ( $\mathrm{w} t \%)$

$=$ Weight of upgraded biocrude oil / Weight of biocrude oil $\times 100$

Solid product yield ( $w \mathrm{t} \%)$

$=$ Weight of produced solid product $/$ Weight of biocrude oil $\times 100$

Gas product yield $(\mathrm{wt} \%)=$ Weight of produced gas $/$ Weight of biocrude oil $\times 100$

In preparation for catalytic cracking, $54 \mathrm{~g}$ of biocrude oil and $6 \mathrm{~g}$ of Ni/MCM-41 catalyst $(9: 1, w / w)$ were fed into the autoclave reactor. Prior to the reaction, the reactor pressure was increased to 30 bar to test for any $\mathrm{N}_{2}$ leakage. After a satisfactory test result was obtained, the reactor pressure was decreased back to 0 bar. The reactor was heated with an electric heating system at a rate of $10{ }^{\circ} \mathrm{C} / \mathrm{min}$ to $400^{\circ} \mathrm{C}$ under a constant stirring rate of $400 \mathrm{rpm}$. When the temperature reached $400{ }^{\circ} \mathrm{C}$, the reaction was stopped and then cooled to room temperature by water circulation. All of the gas, liquid, and solid products were collected from the reactor for analysis. The subsequent procedure was the same as detailed above.

\subsection{Analyses}

The fatty acid contents of the spent coffee grounds and coffee biocrude oil were analyzed using the modified direct esterification method. To that end, samples totaling approximately $10 \mathrm{mg}$ were first put into a vial. Two milliliters of chloroform-methanol mixture $(2: 1, v / v)$ was added to the samples, and the solution was then vigorously agitated for $10 \mathrm{~min}$. With one milliliter of chloroform solution containing heptadecanoic acid (SigmaAldrich) as an internal standard ( $500 \mu \mathrm{g} / \mathrm{L}), 1 \mathrm{~mL}$ of methanol, and $300 \mu \mathrm{L}$ of $\mathrm{H}_{2} \mathrm{SO}_{4}$ were sequentially added to the vial, and the solution was vortex-mixed for $5 \mathrm{~min}$. The vial was then submerged in a $100{ }^{\circ} \mathrm{C}$ water bath for $10 \mathrm{~min}$, after which it was cooled to room temperature, supplemented with $1 \mathrm{~mL}$ distilled water, and intensely mixed for $5 \mathrm{~min}$. After centrifugation, the lower layer (the organic phase) was injected into a gas chromatograph (Agilent 7890, Santa Clara, CA, USA).) for fatty acid methyl ester (FAME) analysis using the INNOWAX column $(30 \mathrm{~m} \times 0.32 \mathrm{~mm} \times 0.5 \mu \mathrm{m}$; Agilent, Santa Clara, CA, USA). The initial oven temperature was $50{ }^{\circ} \mathrm{C}$ for $1 \mathrm{~min}$, which was thereafter increased to $200{ }^{\circ} \mathrm{C}$ at a rate of $15^{\circ} \mathrm{C} / \mathrm{min}$, then maintained for $9 \mathrm{~min}$, which was subsequently increased again to $250{ }^{\circ} \mathrm{C}$ at a rate of $2{ }^{\circ} \mathrm{C} / \mathrm{min}$, and finally maintained for $2 \mathrm{~min}$. Mix RM3 (C14:0 C24:0), Mix RM5 (C8:0 C18:2), and GLC50 (C16:1 C22:1) (Supelco) were utilized as the fatty acid standards. The weight of each of the fatty acids was calculated quantitatively through standard calibration. The other reagents used were of analytical grade.

The composition analyses of the coffee biocrude oil, plastic pyrolysis oil, and upgraded biocrude oils were performed on an Agilent 7890A gas chromatograph (HP-5 column, $30 \mathrm{~m} \times 0.32 \mathrm{~mm} \times 0.2 \mu \mathrm{m}$ ) equipped with a mass spectrometer (5975C). The carrier gas was He of $99.999 \%$ purity. The oven temperature increased from 45 to $250{ }^{\circ} \mathrm{C}$ at a rate of $8{ }^{\circ} \mathrm{C} / \mathrm{min}$. The compounds were identified using the National Institute of Standards and Technology (NIST) Mass Spectral Library. The analyses of the gas products were performed using an Agilent GC with a TCD (Carboxen 1000 column) for $\mathrm{H}_{2}, \mathrm{CO}, \mathrm{CO}_{2}$, and $\mathrm{CH}_{4}$, and with a FID (Carboxen 1000 column) for $\mathrm{C}_{2} \mathrm{H}_{4}, \mathrm{C}_{2} \mathrm{H}_{6}, \mathrm{C}_{3} \mathrm{H}_{6}$, and $\mathrm{C}_{3} \mathrm{H}_{8}$. The elemental analyses were performed with a FLASH 2000, and the higher heating value (HHV) was calculated according to the DIN 51900 standard.

\section{Results and Discussion}

\subsection{Characterization of Spent Coffee Grounds, Coffee Biocrude Oil, and Plastic Pyrolysis Oil}

The fatty acid contents and the compositions of the spent coffee grounds and coffee biocrude oil are summarized in Table 1 . The total fatty acid content of the spent coffee grounds was $173.5 \mathrm{mg} / \mathrm{g}$, which means that they contained $17.4 \mathrm{wt} \%$ lipids, including 
triglycerides and free fatty acids based on their dry weight. The palmitic acid (C16:0) composition was $35.2 \mathrm{wt} \%$ total fatty acids, and the linoleic acid (C18:2) composition was $44.0 \mathrm{wt} \%$ total fatty acids. Goh et al. [18] reported a lipid extraction yield from spent coffee grounds of $14.5 \mathrm{wt} \%$ based on ultrasonic extraction, and their two main fatty acids were palmitic acid (32.8 wt\%) and linoleic acid (44.1 wt\%). Somnuk et al. [24] obtained a $14.7 \mathrm{wt} \%$ lipid extraction yield from spent coffee grounds using hexane, and the contents of their palmitic and linoleic acids were 34.4 and $43.1 \mathrm{wt} \%$, respectively.

Table 1. Fatty acid contents and composition of spent coffee grounds and coffee biocrude oil by GC analysis.

\begin{tabular}{ccccc}
\hline & Spent Coffee Grounds & & Coffee Biocrude Oil \\
\hline Fatty Acids & Content (mg/g) & Composition (wt $/ \mathbf{0})$ & Content (mg/g) & Composition (wt $\%)$ \\
\hline Palmitic acid (C16:0) & 61.1 & 35.2 & 99.7 & 59.4 \\
Stearic acid (C18:0) & 12.2 & 7.0 & 19.3 & 11.5 \\
Oleic acid (C18:1) & 13.8 & 8.0 & 17.5 & 10.4 \\
Linoleic acid (C18:2) & 76.3 & 44.0 & 1.2 & 0.6 \\
Linolenic acid (C18:3) & 3.5 & 2.0 & 7.6 & 4.5 \\
Arachidic acid (C20:0) & 4.9 & 2.8 & 3.0 & 1.8 \\
Eicosenoic acid (C20:1) & 0.5 & 0.3 & 1.8 & 1.1 \\
Behenic acid (C22:0) & 1.2 & 0.7 & 167.9 & 100.0 \\
\hline Total & 173.5 & 100.0 & \\
\hline
\end{tabular}

In the present study, the total fatty acid content of the coffee biocrude oil was $167.9 \mathrm{mg} / \mathrm{g}$, which means that the oil contained $16.8 \mathrm{wt} \%$ lipids, including triglycerides and free fatty acids based on its dry weight. The palmitic acid (C16:0) composition was $59.4 \mathrm{wt} \%$ of total fatty acids. The stearic acid (C18:0), oleic acid (C18:1), and linoleic acid (C18:2) compositions were $11.5,10.4$, and $10.6 \mathrm{wt} \%$ total fatty acids, respectively. While the major fatty acids of the spent coffee grounds were C16:0 and C18:2, that of the coffee biocrude oil was only C16:0. The [C16:0]:[C18:0]:[C18:1]:[C18:2] weight ratios of the spent coffee grounds and coffee biocrude oil were 100:20:23:125 and 100:19:18:18, respectively. After fast pyrolysis, linoleic acid (C18:2) containing two double bonds was noticeably depleted. Although C18:1, with one double bond at position 9, was stable during high-temperature pyrolysis $\left(500-600^{\circ} \mathrm{C}\right), \mathrm{C} 18: 2$ with two double bonds at positions 9 and 12 is thought to have been converted to other molecules during pyrolysis. Primaz et al. [16] analyzed coffee biocrude oil under the optimal condition $\left(500^{\circ} \mathrm{C}\right)$ using two-dimensional GC. The major compounds were, similar to in the present study, palmitic acid (19.2 area\%), oleic acid (11.1 area \%), and stearic acid (9.9 area\%). In the present study, the content of linoleic acid was decreased by the pyrolysis of coffee grounds. In Primaz's study, no linoleic acid was observed. The present GC graphs of the spent coffee grounds and coffee biocrude oil indicated peaks of C16:0, C18:0, C18:1, C18:2, and C20:0, among others (Figure 1). On the GC graph of the coffee biocrude oil, many small peaks before the $\mathrm{C} 16: 0$ peak, representing hydrocarbons, aromatics, and phenols, were also observed.

The contents of the $\mathrm{C}, \mathrm{H}, \mathrm{N}$, and $\mathrm{O}$ elements and higher heating values (HHVs) of the spent coffee grounds, coffee biocrude oil, and plastic pyrolysis oil are summarized in Table 2. The carbon content was the highest for plastic pyrolysis oil $(80.5 \mathrm{wt} \%)$ and the oxygen content was the highest for spent coffee grounds $(34.8 \mathrm{wt} \%)$. Due to the fact that high oxygen contents, affected by oxygenated compounds, make pyrolysis oil reactive and unstable, they need to be lowered in the process of pyrolysis oil upgrading. The $\mathrm{N}$ compounds of spent coffee grounds and coffee biocrude oil originate from the caffeine, protein, and trigonelline compounds [25]. In the present study, the HHVs were 24.4, 33.3, and $40.6 \mathrm{MJ} / \mathrm{kg}$ for the spent coffee grounds, coffee biocrude oil, and plastic pyrolysis oil, respectively. The coffee biocrude oil containing lipids of triglycerides and free fatty acids showed a larger HHV than a previous study's sawdust pyrolysis oil, which showed a $33.9 \mathrm{wt} \%$ oxygen content and a 25.2 MJ/kg HHV [23]. In the study of Somnuk et al. [24], 
the contents of $\mathrm{C}, \mathrm{H}, \mathrm{N}$, and $\mathrm{O}$ for spent coffee grounds were 53.0, 6.8, 2.1, and 38.1\%, respectively. This composition was similar to that of our current study. Their HHV, meanwhile, was $23.1 \mathrm{MJ} / \mathrm{kg}$. Bok et al. [26] reported that the contents of $\mathrm{C}, \mathrm{H}, \mathrm{N}$, and O for coffee biocrude oil were 54.3, 7.4, 3.1, and $35.3 \%$, respectively, and that the HHV was $23.2 \mathrm{MJ} / \mathrm{kg}$. After fast pyrolysis, the $\mathrm{O}$ content was still high and the heating value was low, as the moisture content of the biocrude oil was $24.0 \mathrm{wt} \%$. In the present study, biocrude oil was upgraded after evaporation in order to enhance its efficiency, resulting in the oxygen content decreasing to $16.9 \mathrm{wt} \%$. Zhang et al. [20] produced pyrolysis oil with a HHV of $39.1 \mathrm{MJ} / \mathrm{kg}$ from a plastic mixture, and the contents of $\mathrm{C}, \mathrm{H}, \mathrm{N}$, and $\mathrm{O}$ for plastic pyrolysis oil were 88.0, 8.1, 0.9, and 3.0\%, respectively. Because plastic pyrolysis oil shows very high HHVs with low oxygen contents, the properties of coffee biocrude oil are expected to be further improved through the process of blending with plastic pyrolysis oil.

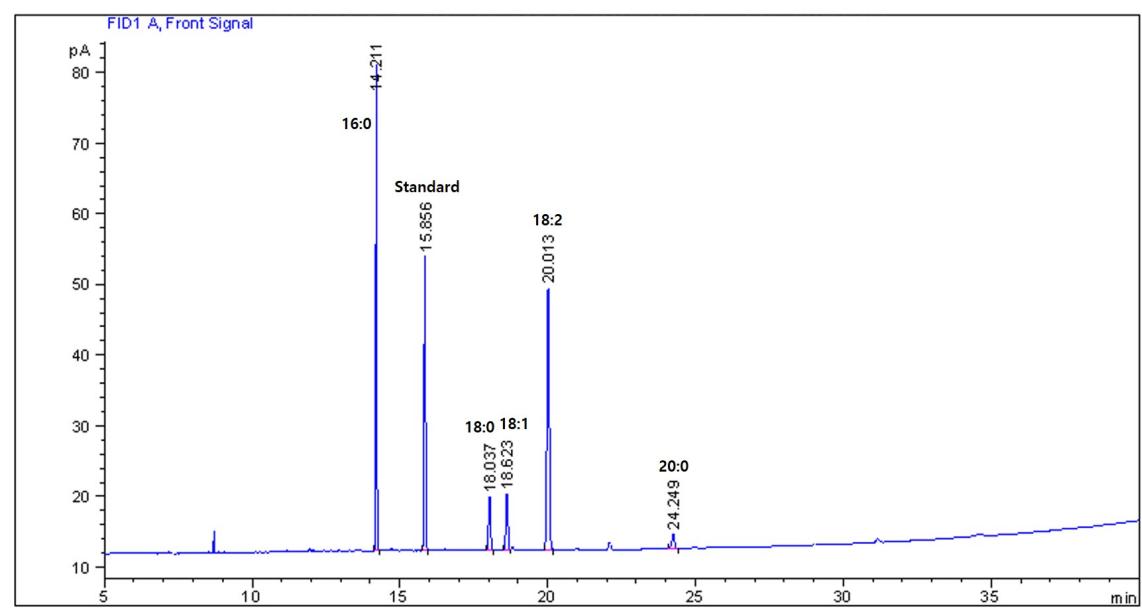

(a)

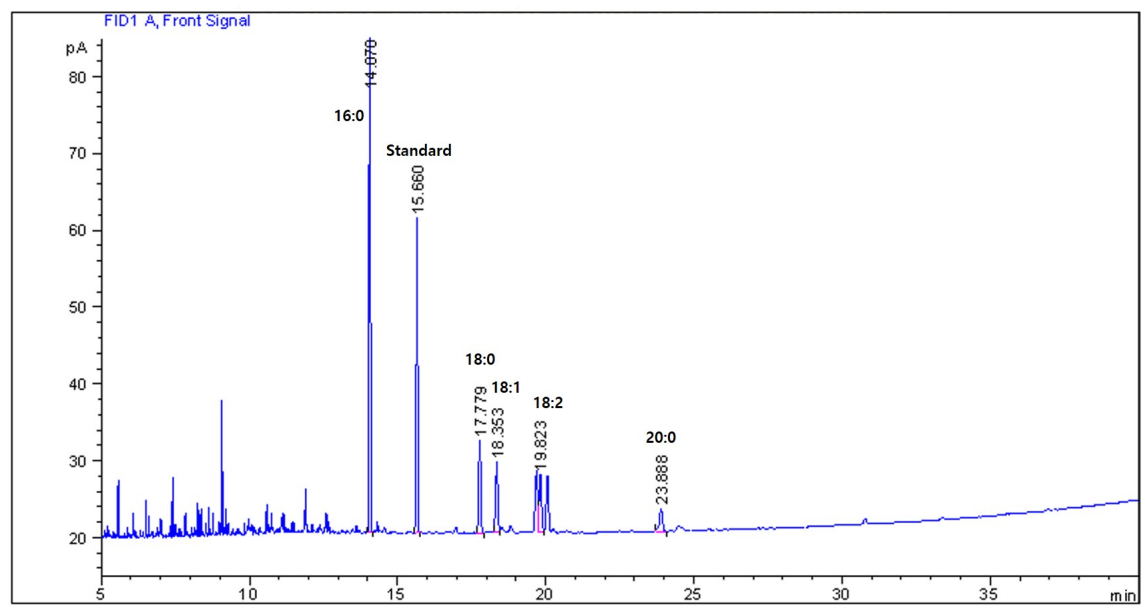

(b)

Figure 1. Fatty acid distributions of (a) spent coffee grounds and (b) coffee biocrude oil by GC analysis.

\subsection{Upgrading Coffee Biocrude Oil by Supercritical Ethanol Reaction}

The physical properties of catalysts are summarized in Table 3. The BET surface areas of AC and MCM-41 were 687.9 and $1010.2 \mathrm{~m}^{2} / \mathrm{g}$, respectively. The BET surface area of $\mathrm{MgNiMo} / \mathrm{AC}$ and Ni/MCM-41 decreased to 518.4 and $465.8 \mathrm{~m}^{2} / \mathrm{g}$ compared with the original catalysts, respectively. 
Table 2. Elemental compositions of spent coffee grounds, coffee biocrude oil, and plastic pyrolysis oil.

\begin{tabular}{cccc}
\hline & Spent Coffee Grounds & Coffee Biocrude Oil & Plastic Pyrolysis Oil \\
\hline $\mathrm{C}(\mathrm{wt} \%)$ & 55.3 & 70.0 & 80.5 \\
$\mathrm{H}(\mathrm{wt} \%)$ & 7.4 & 9.0 & 11.3 \\
$\mathrm{~N}(\mathrm{wt} \%)$ & 34.8 & 3.8 & 0.6 \\
$\mathrm{O}(\mathrm{wt} \%)$ & 24.4 & 16.9 & 7.6 \\
\hline $\mathrm{HHV}(\mathrm{MJ} / \mathrm{kg})^{a}$ & 24.4 & 33.3 & 40.6 \\
\hline${ }^{a}$ Calculated from Channiwala equation: HHV $=0.3491 \mathrm{C}+1.1783 \mathrm{H}-0.1034 \mathrm{O}-0.0151 \mathrm{~N}$.
\end{tabular}

Table 3. Physical properties of catalysts.

\begin{tabular}{cccc}
\hline & BET Surface Area $\left(\mathbf{m}^{2} / \mathbf{g}\right)$ & Pore Volume $\left(\mathrm{cm}^{3} / \mathbf{g}\right)$ & Avg. Pore Diameter $(\mathbf{n m})$ \\
\hline AC & 687.9 & 0.56 & 3.25 \\
MgNiMo/AC & 518.4 & 0.45 & 3.51 \\
MCM-41 & 1010.2 & 0.92 & 3.17 \\
Ni/MCM-41 & 465.8 & 0.32 & 3.06 \\
\hline
\end{tabular}

Coffee biocrude oil was upgraded using a supercritical ethanol reaction with and without a catalyst. The major components of the coffee biocrude oil were acids (40.9 area $\%)$, hydrocarbons (20.3 area\%), phenols (10.6 area\%), and aromatics (8.2 area\%) (Figure 2). The major acids included palmitic acid (C16:0), stearic acid (C18:0), oleic acid (C18:1), and linoleic acid (C18:2). Primaz et al. [16] reported that coffee biocrude oil contained acids (46.0 area \%), esters (12.0 area \%), hydrocarbons (13.0 area \%), phenols (6.0 area \%), and aromatics (5.0 area\%). In the present study, the content of esters was lower ( 3.1 area $\%)$ than the corresponding result of Primaz et al. [16]. The major component was very different with sawdust pyrolysis oil, according to an earlier study: phenols (46.1 area\%), with ester, aldehyde, and alcohol contents of 11.0, 10.3, and 9.4 area \%, respectively, [23]. Among the phenols in that study, whereas the sawdust pyrolysis oil consisted of both methoxy phenol and alkyl phenol, the former having higher content, coffee biocrude oil mainly consisted of alkyl phenol.

Table 4. Compositions of fatty acid ethyl esters of upgraded coffee biocrude oils by GC-MS analysis.

\begin{tabular}{cccc}
\hline & EtOH & EtOH-AC & EtOH-MgNiMo/AC \\
\hline C16:0 ethyl ester (area\%) & 30.3 & 31.9 & 31.2 \\
C18:0 ethyl ester (area\%) & 9.2 & 10.1 & 9.1 \\
C18:1 ethyl ester (area\%) & 10.9 & 11.7 & 17.0 \\
C18:2 ethyl ester (area\%) & 14.2 & 13.7 & 8.9 \\
\hline Total & 64.6 & 67.4 & 66.2 \\
\hline
\end{tabular}

During a supercritical ethanol reaction, the esterification of fatty acids with mainly ethanol occurs. Under the supercritical ethanol condition of $340{ }^{\circ} \mathrm{C}$, the fatty acids of biocrude oil are converted to esters without any catalyst. Farobie et al. [27] reported that canola oil was converted to biodiesel of $100 \%$ fatty acid methyl ester under a reaction time of $10 \mathrm{~min}$ at $350{ }^{\circ} \mathrm{C}$ and an oil-to-methanol molar ratio of 1:40 without catalyst. Akkarawatkhoosith et al. [28] produced biodiesel with $98.5 \%$ fatty acid ethyl ester from palm oil under a residence time of $5.2 \mathrm{~min}$ at $370{ }^{\circ} \mathrm{C}$ and an oil-to-ethanol molar ratio of 1:16 without catalyst. The ester content of coffee biocrude oil was 3.1 area $\%$, but after a supercritical ethanol reaction without a catalyst, the ester content increased to 73.8 area\% (Figure 2). The MgNiMo/AC catalyst was employed in the present experiment as it had shown good performance in the deoxygenation of bio-tar and biomass pyrolysis oil [10,23]; with $\mathrm{MgNiMo} / \mathrm{AC}$, the oxygen content of bio-tar decreased from 31.3 to $12.5 \%$ during a supercritical ethanol reaction at $350{ }^{\circ} \mathrm{C}$ for $1 \mathrm{~h}$ [10]; meanwhile, in the other study using the same catalyst, the oxygen content of sawdust pyrolysis oil decreased from 33.9 to $14.6 \%$ during a supercritical ethanol reaction at $340{ }^{\circ} \mathrm{C}$ for $2 \mathrm{~h}$ [23]. When $\mathrm{AC}$ and $\mathrm{MgNiMo} / \mathrm{AC}$ catalysts were used in the present study, the compositions of the upgraded oils were 
similar to those without catalyst. The reason was that the esterification of fatty acids occurred without any catalyst under the supercritical ethanol condition of $340^{\circ} \mathrm{C}$. After the supercritical reaction, the major component of the upgraded biocrude oil was C16:0 ethyl ester in all three cases because palmitic acid (C16:0), which was the major component of the coffee biocrude oil, was esterified with ethanol (Table 4). The contents of C18:0 ethyl ester, C18:1 ethyl ester, and C18:2 ethyl ester were roughly within a third to a half of that of C16:0 ethyl ester in area\% (Table 4). The other components were hydrocarbons and phenols (Figure 2).

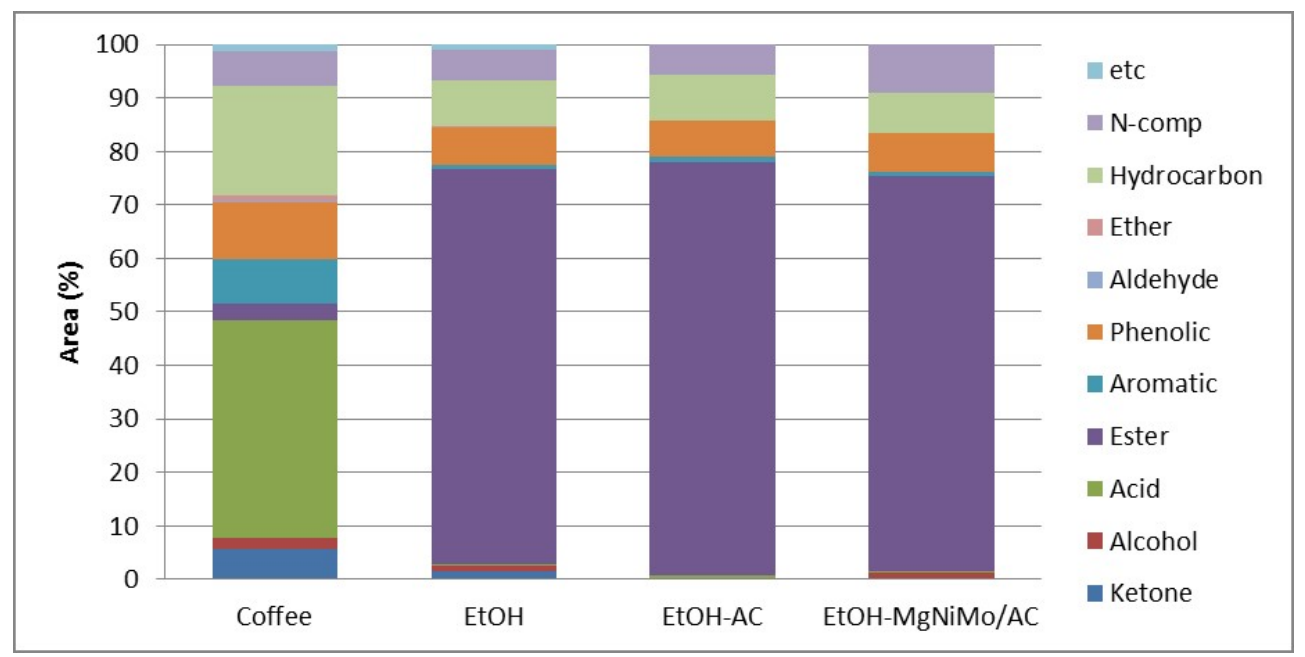

Figure 2. Compositions of coffee biocrude oil and upgraded coffee biocrude oils by GC-MS analysis (reaction conditions: biocrude oil $=20 \mathrm{~g}$, ethanol $=80 \mathrm{~g}$, $\mathrm{AC}$ or $\mathrm{MgNiMo} / \mathrm{AC}=4 \mathrm{~g}$, temperature $=$ $340{ }^{\circ} \mathrm{C}$, reaction time $=2 \mathrm{~h}, \mathrm{~N}_{2}$ initial pressure $=30 \mathrm{bar}$ ).

As a result of the upgrading reaction, the oxygen contents decreased from $16.9 \mathrm{wt} \%$ of coffee biocrude oil to less than $10 \mathrm{wt} \%(9.9,9.1$, and $8.5 \mathrm{wt} \%$ for oils upgraded by supercritical ethanol, supercritical ethanol with $\mathrm{AC}$, and supercritical ethanol with $\mathrm{MgN}$ $\mathrm{iMo} / \mathrm{AC}$, respectively). Because the $-\mathrm{COOH}$ group of fatty acids had been converted to the $-\mathrm{COOC}_{2} \mathrm{H}_{5}$ ester with $-\mathrm{C}_{2} \mathrm{H}_{5}$ ethanol (Equation (1)), and $-\mathrm{C}_{2} \mathrm{H}_{5}$ ethanol was bound to several compounds, such as phenols, the overall oxygen content decreased. Prajitno et al. [7] reported that the oxygen content of pyrolysis bio-oil derived from empty palm fruit bunch decreased from 26.8 to $12.6 \%$ during a supercritical ethanol reaction at $400{ }^{\circ} \mathrm{C}$ for $30 \mathrm{~min}$ without catalyst. In the present study, when $\mathrm{MgNiMo} / \mathrm{AC}$ was used as a catalyst, the oxygen content of coffee crude oil additionally decreased to $8.5 \mathrm{wt} \%$. As shown in Figure 3, the hydrogen content with $\mathrm{MgNiMo} / \mathrm{AC}$ after the reaction was higher than in the cases without catalyst or with AC. Hydrogen can be efficiently produced from ethanol under the $\mathrm{MgNiMo} / \mathrm{AC}$ catalyst condition (Equation (2)) [23]. $\mathrm{CO}$ and $\mathrm{CH}_{4}$ were also produced from ethanol.

$$
\begin{gathered}
\mathrm{RCOOH}+\mathrm{C}_{2} \mathrm{H}_{5} \mathrm{OH} \rightarrow \mathrm{RCOOC}_{2} \mathrm{H}_{5}+\mathrm{H}_{2} \mathrm{O} \\
\mathrm{C}_{2} \mathrm{H}_{5} \mathrm{OH} \rightarrow \mathrm{CO}+\mathrm{CH}_{4}+\mathrm{H}
\end{gathered}
$$

Therefore, MgNiMo/AC enhanced the production of hydrogen, which reacted with the biocrude oil, resulting in the oxygen content decreasing through deoxygenation. Some hydrogen was consumed in the reaction with biocrude oil, the rest remaining after the reaction. However, for upgrading coffee biocrude oil containing high fatty acids, $\mathrm{MgNiMo} / \mathrm{AC}$ was not noticeably effective as the main reaction was esterification. The HHVs were 33.3, $37.0,37.5$, and $38.0 \mathrm{MJ} / \mathrm{kg}$ for coffee biocrude oil, oil upgraded by supercritical ethanol, oil upgraded by supercritical ethanol with $A C$, and oil upgraded by supercritical ethanol with $\mathrm{MgNiMo} / \mathrm{AC}$, respectively. After oil upgrading, the heating values were not significantly different. According to the report of Prajitno et al. [7], the heating value of pyrolysis 
bio-oil from empty palm fruit bunch increased to $34.1 \mathrm{MJ} / \mathrm{kg}$ at $400{ }^{\circ} \mathrm{C}$ supercritical ethanol without a catalyst.

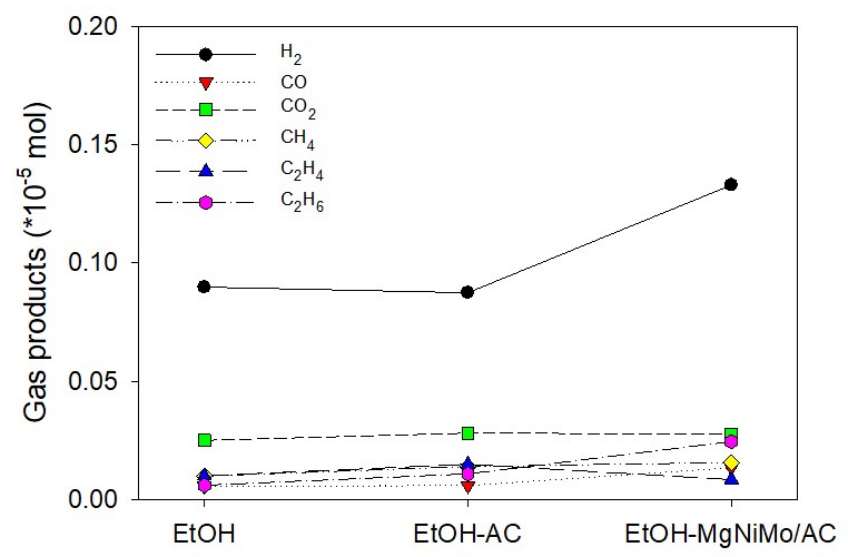

Figure 3. Gas production after supercritical reaction (reaction conditions: biocrude oil $=20 \mathrm{~g}$, ethanol $=80 \mathrm{~g}, \mathrm{AC}$ or $\mathrm{MgNiMo} / \mathrm{AC}=4 \mathrm{~g}$, temperature $=340{ }^{\circ} \mathrm{C}$, reaction time $=2 \mathrm{~h}, \mathrm{~N}_{2}$ initial pressure $=$ 30 bar).

\subsection{Upgrading Coffee Biocrude Oil by Supercritical Ethanol Reaction with Plastic Pyrolysis Oil}

The plastic pyrolysis oil employed in the present experimentation mainly consisted of hydrocarbons and aromatics, unlike the acids and hydrocarbons in the coffee crude oil (Figure 4a). Because chlorinated compounds are hazardous, and poisonous to catalysts, and have acidic characteristics, polyvinyl chloride is not a desirable plastic. Pyrolysis oils produced from polyethylene and polystyrene are desirable for blending with biofuels. The mixture of coffee biocrude oil and plastic pyrolysis oil was reacted with supercritical ethanol without a catalyst to upgrade the properties of the former. The weight ratios of coffee biocrude oil to plastic pyrolysis oil were 1:0, 1:0.5, 1:1, and 1:2. As plastic pyrolysis oil is rich in hydrocarbons and aromatics, the low-grade properties of oxygen-rich coffee biocrude oil can be improved in combination with plastic pyrolysis oil [21]. After the supercritical ethanol reaction of coffee biocrude oil mixture, the major product was esters, produced by the esterification of fatty acids. When the blending ratios of plastic pyrolysis increased, the contents of hydrocarbons, phenols, and aromatics gradually increased with the decrease in the ester content.

Biocrude oil is typically immiscible with hydrocarbons due to the high oxygen content [29], which renders it immiscible with conventional fossil fuels as well [7]. When the hydrocarbon decene, instead of plastic pyrolysis oil with black color, was added to coffee biocrude oil to determine the miscibility of the two pyrolysis oils, the two phases were not completely miscible. As shown in Figure 5a, the top layer was decene and the bottom layer was coffee biocrude oil. However, after the supercritical ethanol reaction of the mixture of coffee biocrude oil and decene $(1: 1, w / w)$ under the same conditions $\left(340^{\circ} \mathrm{C}\right.$ and $2 \mathrm{~h}$ ), the product was miscible into one phase (Figure $5 \mathrm{~b}$ ). Therefore, upgraded coffee biocrude oil produced through a supercritical ethanol reaction with plastic pyrolysis oil is expected to have better properties than oil produced by the mechanical blending of plastic pyrolysis oil and coffee biocrude oil. 


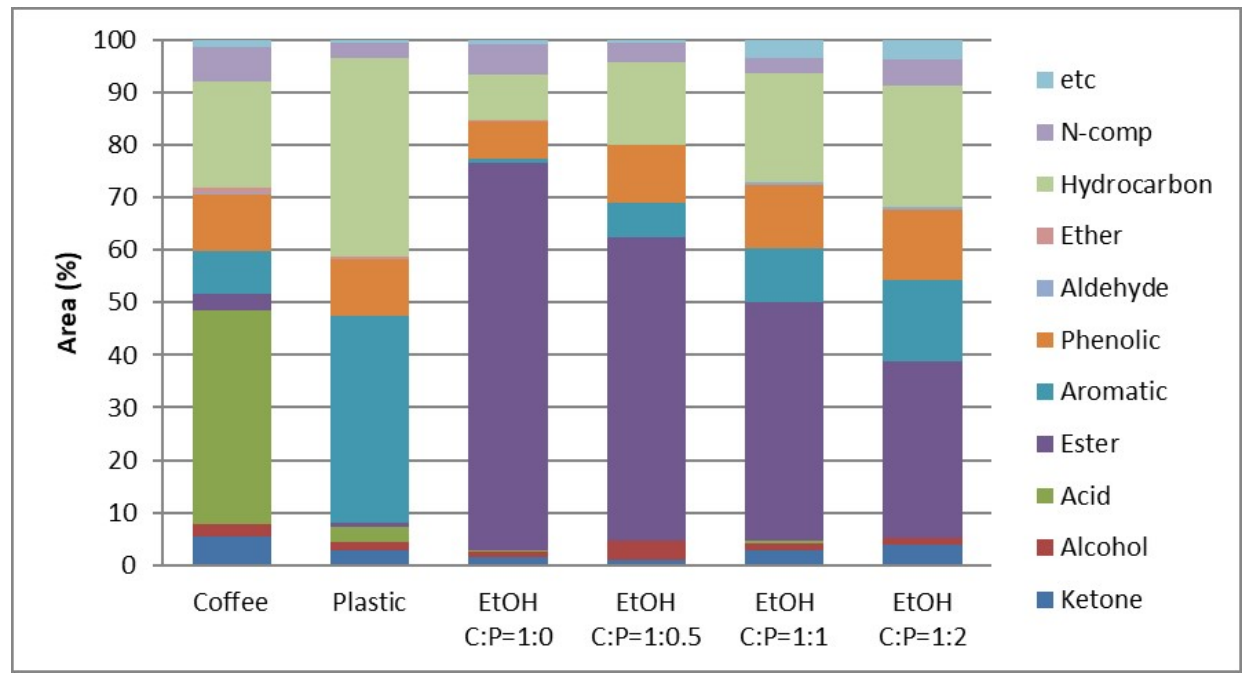

(a)

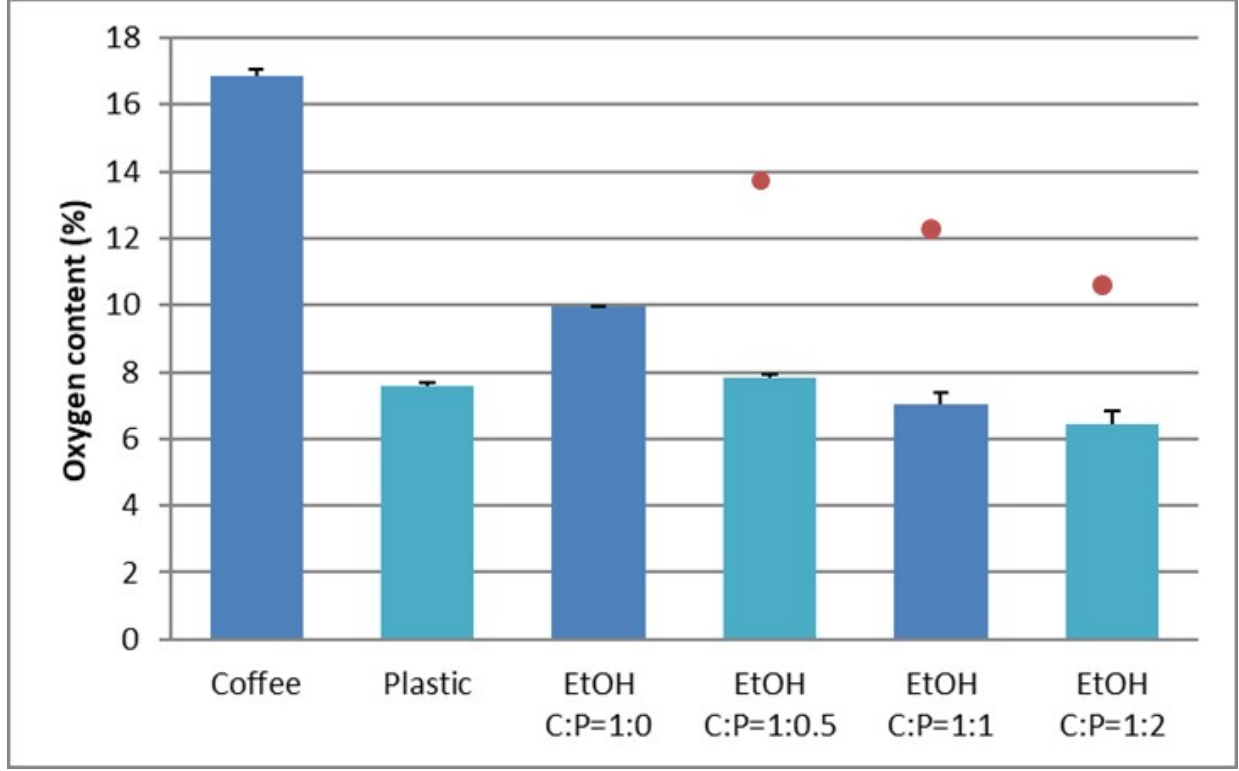

(b)

Figure 4. Characteristics of coffee biocrude oil, plastic pyrolysis oil, and upgraded coffee biocrude oils with plastic pyrolysis oil under supercritical ethanol. (a) Compositions by GC-MS analysis (C:P is the weight ratio of coffee biocrude oil to plastic pyrolysis oil). (b) Oxygen contents (reaction conditions: biocrude oil $=20 \mathrm{~g}$; ethanol $=80 \mathrm{~g}$; plastic pyrolysis oil $=10,20$, and $40 \mathrm{~g}$; temperature $=$ $340{ }^{\circ} \mathrm{C}$; reaction time $=2 \mathrm{~h} ; \mathrm{N}_{2}$ initial pressure $=30 \mathrm{bar}$.

The initial oxygen contents of the coffee biocrude oil and plastic pyrolysis oil were 16.9 and $7.6 \mathrm{wt} \%$, respectively (Figure $4 \mathrm{~b}$ ). If the two pyrolysis oils were mechanically blended at the ratios of 1:0.5, 1:1, and 1:2, their oxygen contents would be 13.8, 12.2, and $10.7 \mathrm{wt} \%$, respectively (calculated mathematically), although the complete one phase of oil could not be formed (red circles in Figure $4 \mathrm{~b}$ ). However, after the upgrading reaction under the ethanol condition, the oxygen contents were decreased through the supercritical ethanol reaction, yielding 7.8, 7.0, and $6.4 \mathrm{wt} \%$, respectively. Hydrogen produced from ethanol reacted with the biocrude oil, and the oxygen content was decreased by deoxygenation. Because the - $\mathrm{COOH}$ group of fatty acids was converted to $-\mathrm{COOC}_{2} \mathrm{H}_{5}$ ester, and $-\mathrm{C}_{2} \mathrm{H}_{5}$ ethanol was bound to some of the compounds of both coffee and plastic oil, the overall oxygen content was further decreased. 


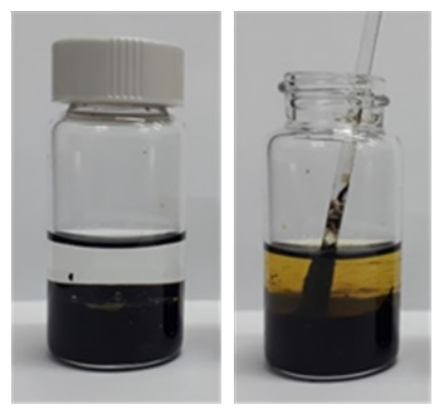

(a)

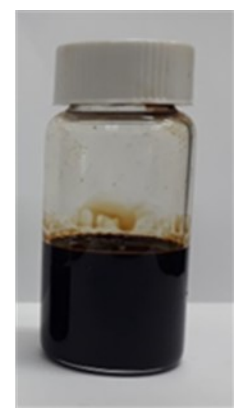

(b)

Figure 5. Miscibility of (a) mixture of coffee crude oil and decene before/after stirring and (b) reaction product of coffee crude oil and decene under supercritical ethanol.

The heating values of the pyrolysis oils and upgraded coffee biocrude oils are summarized in Table 5. Plastic pyrolysis oil showed the highest heating value with a low oxygen content. When the blending ratio of plastic pyrolysis oil increased, the heating values of the upgraded oils also increased. The direct co-pyrolysis of biomass and waste plastic for high-grade biofuel production (an alternative to oil upgrading through the blending of two pyrolysis oils from biomass and waste plastic, as in the present study) has also been studied [30-32]. Elsewhere, when co-pyrolysis at the ratio of 1:1 of waste wood chip and polypropylene was performed at $500{ }^{\circ} \mathrm{C}$, the oxygen content of the upgraded biocrude oil decreased from 42.3 to $10.9 \%$ and its HHV increased from 19.9 to $45.0 \mathrm{MJ} / \mathrm{kg}$ [33]. In another study, when co-pyrolysis at the ratios of 4:0, 3:1, 2:2, and 1:3 of waste newspaper and polyethylene was performed at $500-800{ }^{\circ} \mathrm{C}$, the oxygen contents of upgraded biocrude oils decreased from 49.3 to 56.8 to 26.6-32.6, 14.9-20.6, and 2.4-5.4\%, respectively, and the HHV increased from 14.2 to 16.8 to $21.2-24.8,28.0-2-34.4$, and $34.8-39.8 \mathrm{MJ} / \mathrm{kg}$, respectively [34]. Zanella et al. [35] evaluated the co-pyrolysis of polypropylene and coffee waste at temperatures of $360-420{ }^{\circ} \mathrm{C}$. When the fraction of polypropylene increased, the quantity of light liquid products decreased, while the fraction of heavy condensate products rose. Meanwhile, in the same study, when co-pyrolysis at the ratio of 1:1 polypropylene and coffee wastes was performed at $420{ }^{\circ} \mathrm{C}$, the liquid yield was $71.7 \mathrm{wt} \%$, whereas at $360{ }^{\circ} \mathrm{C}$, the liquid yield was just $25.6 \mathrm{wt} \%$. As all of these comparative results reveal, the present upgrading process has two advantages over the earlier processes: the effective utilization of waste plastic, and property improvement of biocrude oil.

Table 5. Heating values of coffee biocrude oil, plastic pyrolysis oil, and upgraded coffee biocrude oils.

\begin{tabular}{ccccccc}
\hline & \multirow{2}{*}{ Coffee Biocrude Oil } & \multirow{2}{*}{ Plastic Pyrolysis Oil } & \multicolumn{4}{c}{ Upgraded Coffee Biocrude Oils (Supercritical EtOH) } \\
\cline { 4 - 7 } & & & C:P ${ }^{*}=\mathbf{1 : 0}$ & C:P = 1:0.5 & C:P = 1:1 & C:P = 1:2 \\
\hline $\mathrm{HHV}(\mathrm{MJ} / \mathrm{kg})^{a}$ & 33.3 & 40.6 & 37.0 & 38.8 & 39.6 & 40.1 \\
\hline
\end{tabular}

${ }^{*} \mathrm{C}: \mathrm{P}$ is the weight ratio of coffee biocrude oil to plastic pyrolysis oil. ${ }^{a}$ Calculated from Channiwala equation: $\mathrm{HHV}=0.3491 \mathrm{C}+1.1783 \mathrm{H}-$ $0.1034 \mathrm{O}-0.0151 \mathrm{~N}$.

\subsection{Catalytic Cracking of Coffee Crude Oil by Ni/MCM-41 Catalyst without Supercritical Ethanol}

The Ni/MCM-41 catalyst has been employed for catalytic cracking of coffee crude oil using a batch reactor. Hu et al. [36] reported that a char-supported Ni catalyst showed good performance for the catalytic cracking of biomass tar: the content of single-ring aromatics increased and that of $\mathrm{O}$-containing compounds decreased relative to the char catalyst without $\mathrm{Ni}$; the oxygen content of biomass tar also decreased from 31.9 to 30.1 and $7.8 \mathrm{wt} \%$ for char and $\mathrm{Ni} /$ char, respectively. The MCM-41 catalyst has been used for the catalytic cracking of oleic acid, with the result being that the content of aromatic compounds increased with the increase in reaction temperature and reaction time. In addition, at $400{ }^{\circ} \mathrm{C}$, large amounts of hydrocarbons with low aromatics content were produced from oleic acids by MCM-41 [37]. In the study of Twaiq et al. [38], the MCM-41 catalyst showed weak 
Bronsted and Lewis acidity. This weak acidity led to the cracking of the linear chains (fatty acids) in palm oil, linear paraffin and olefins without further isomerization to napthenes or aromatics. In the present study, the pressure was increased to 50.6 bar during the catalytic cracking of coffee biocrude oil at $400{ }^{\circ} \mathrm{C}$. The initial hydrocarbons content was 20.3 area\%. The acids (40.9 area\%) with - $\mathrm{COOH}$ were converted to hydrocarbons (66.4 area \%). The amount of aromatics was moderately decreased from 8.2 to 5.5 area $\%$, and the ketones, alcohols, and acids disappeared (Figure 6). The hydrocarbons consisted of C9 to C21, including alkanes, alkenes, and cycloalkanes. During the catalytic cracking of fatty acids, deoxygenation occurred by reactions of dehydration, decarboxylation, decarbonylation, and others [39]. The content of pentadecane (C15) and heptadecane (C17) in hydrocarbons were high at 19.9 and 8.0 area\%, respectively. The major components of the coffee biocrude oil were palmitic acid, stearic acid, oleic acid, and linoleic acid. Note that, when carbon dioxide is removed from palmitic acid, pentadecane can be produced, and when carbon dioxide is removed from stearic acid, heptadecane can be produced [38]. The contents of the alkanes of $\mathrm{C} 13, \mathrm{C} 14$, and C16 were $4.7,6.4$, and 4.1 area\%, respectively. After catalytic cracking, the contents of the nitrogen compounds were increased. The content of pentadecanenitrile was the highest, with 9.4 area\%. Octadecanenitrile, hexadecanamide, and octadecanamine, among others, were observed in the liquid product. Fischer et al. [25] also found nitrogen compounds after catalytic pyrolysis involving spent coffee grounds using ZSM- 5 as a catalyst. They suggested that the amide had been produced from the amidization of acid with ammonia produced from proteinaceous compound and that the nitrile had been produced from amide pyrolysis [25].

After the present study's reaction, the product yields were $37.7,36.5$, and $25.8 \mathrm{wt} \%$ for liquid, coke, and gas, respectively. The heating value of liquid was $41.9 \mathrm{MJ} / \mathrm{kg}$ and the oxygen content was very low, $2.8 \mathrm{wt} \%$. In the study of Mancio et al. [40], the catalytic cracking of crude palm oil at $450{ }^{\circ} \mathrm{C}$ was performed using a $\mathrm{Na}_{2} \mathrm{CO}_{3}$ catalyst. When the catalyst dosage was increased, the concentration of hydrocarbons increased, whereas the concentration of oxygenates decreased. With a $15 \mathrm{wt} \%$ catalyst, the yields of liquid, coke, and gas were 58.0, 16.0, and $12.0 \mathrm{wt} \%$, respectively. Twaiq et al. [41] performed the catalytic cracking of palm oil at $350-450{ }^{\circ} \mathrm{C}$ using HZSM-5, zeolite beta, and ultrastable Y catalysts. At $350{ }^{\circ} \mathrm{C}$ for the HZSM- 5 catalyst, the yields of liquid, coke, and gas were 43.6, 6.1, and $41.8 \mathrm{wt} \%$, respectively.

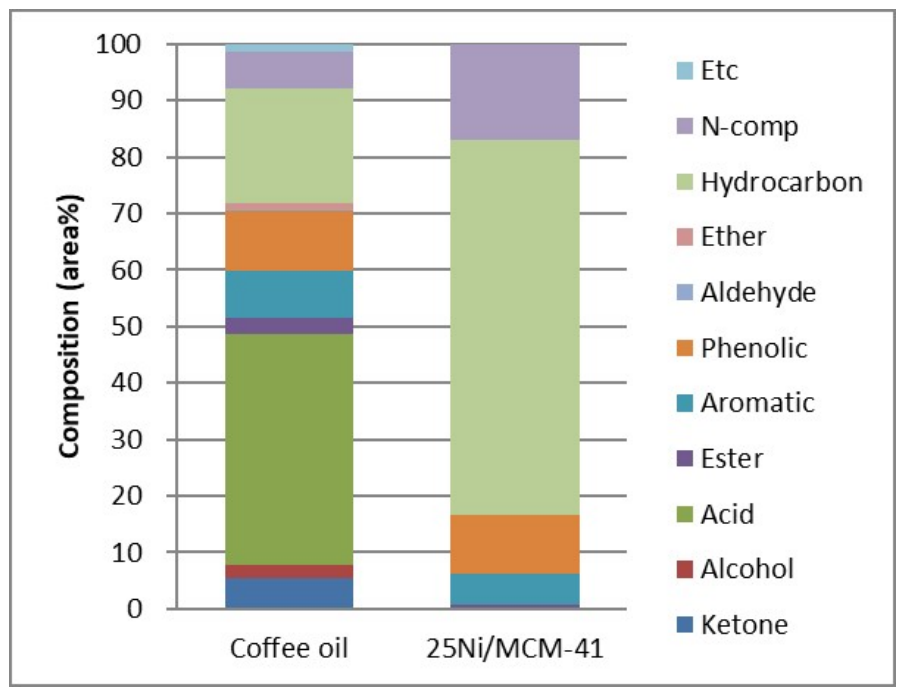

Figure 6. Compositions of coffee biocrude oil and upgraded coffee biocrude oil by catalytic cracking according to GC-MS analysis (reaction conditions: biocrude oil $=54 \mathrm{~g}$, Ni/MCM-41 $=6 \mathrm{~g}$, temperature $=400^{\circ} \mathrm{C}$ ). 


\subsection{Comparison of Methods for Upgrading Coffee Biocrude Oil}

Coffee biocrude oil was upgraded by supercritical ethanol reaction, supercritical ethanol reaction with $\mathrm{MgNiMo} / \mathrm{AC}$ catalyst, supercritical ethanol reaction with plastic pyrolysis oil, and catalytic cracking with Ni/MCM-41. The oxygen contents, HHVs, and liquid yields of the upgraded coffee biocrude oil are summarized in Table 6. The oxygen content of coffee biocrude oil decreased to $9.9 \mathrm{wt} \%$ after the supercritical ethanol reaction. After the catalytic supercritical reaction with $\mathrm{MgNiMo} / \mathrm{AC}$, the oxygen content also decreased $(8.5 \mathrm{wt} \%)$. When the supercritical ethanol reaction was performed after coffee crude oil was blended with plastic pyrolysis oil $(1: 2, w / w)$, the oxygen content was further decreased $(6.4 \mathrm{wt} \%)$. In the supercritical ethanol reaction, the liquid yields slightly increased as the $-\mathrm{C}_{2} \mathrm{H}_{5}$ group originated from ethanol bound to oil compounds, which increased the molecular weights of the products. After the catalytic cracking of coffee pyrolysis oil, the oxygen content was very low, at $2.8 \mathrm{wt} \%$, but the liquid yield was roughly half that of the other reactions. A significant amount of coke was generated after catalytic cracking in the present study. Therefore, the optimal condition for the catalytic cracking of coffee biocrude oil is required. Overall, a supercritical ethanol reaction with plastic pyrolysis oil can improve the properties of coffee biocrude oil and effectively make use of waste plastics. To obtain the full hydrocarbon product, instead of a mixture of hydrocarbon and ester products, catalytic cracking is necessary. Because coffee crude oil contains large amounts of fatty acids, hydrocarbon conversion by catalytic cracking is easier than employing biomass pyrolysis oil. Considering both HHV and liquid yield, supercritical EtOH with MgNiMo/AC had the best performance. MgNiMo/AC had no significant effect on oxygen removal compared to without catalyst, but the liquid yield increased by $5.0 \mathrm{wt} \%$ under the catalyst.

Table 6. Oxygen contents, heating values, and liquid yields of upgraded coffee biocrude oils.

\begin{tabular}{|c|c|c|c|}
\hline Upgrading Methods & $\mathrm{O}(w t \%)$ & HHV (MJ/kg) ${ }^{a}$ & Liquid Yield (wt\%) \\
\hline Coffee biocrude oil & 16.9 & 33.3 & 100.0 \\
\hline Supercritical EtOH & 9.9 & 37.0 & 79.7 \\
\hline $\begin{array}{c}\text { Supercritical EtOH with } \\
\mathrm{MgNiMo} / \mathrm{AC}\end{array}$ & 8.5 & 38.0 & 84.7 \\
\hline $\begin{array}{c}\text { Supercritical EtOH with plastic } \\
\text { pyrolysis oil }\end{array}$ & 6.4 & 40.1 & 65.2 \\
\hline $\begin{array}{c}\text { Catalytic cracking with } \\
\mathrm{Ni} / \mathrm{MCM}-41\end{array}$ & 2.8 & 41.9 & 37.7 \\
\hline
\end{tabular}

${ }^{a}$ Calculated from Channiwala equation: $\mathrm{HHV}=0.3491 \mathrm{C}+1.1783 \mathrm{H}-0.1034 \mathrm{O}-0.0151 \mathrm{~N}$.

\section{Conclusions}

Coffee biocrude oil with high contents of fatty acids (40.9 area\%) was upgraded by means of non-catalytic or catalytic supercritical ethanol reaction, supercritical reaction with plastic pyrolysis oil, and catalytic cracking. Because the fatty acids of the coffee biocrude oil were esterified with supercritical ethanol, the major product was esters. In the supercritical ethanol reaction of coffee biocrude oil with plastic pyrolysis oil $(1: 2(w / w))$, the oxygen content was decreased to $6.4 \mathrm{wt} \%$ and the heating value was increased to $40.1 \mathrm{MJ} / \mathrm{kg}$. Therefore, a supercritical ethanol reaction with plastic pyrolysis oil can be one means of accomplishing two key objectives: improving biocrude oil's properties, and the utilization of abundant waste plastics. It is expected that low-oxygen-content and high-heating-value oil upgraded from coffee biocrude oil has the potential to be used as a biofuel. The use of bioethanol, produced from lignocellulosic biomass, as a supercritical fluid source in the upgrading process will improve the sustainability of the biofuel production process. 
Author Contributions: Conceptualization, J.-Y.P.; formal analysis, M.A.A.K.; investigation, J.-Y.P. and M.A.A.K.; writing—original draft preparation, J.-Y.P.; writing—review and editing, J.-Y.P; M.A.A.K. and I.-G.L.; supervision, I.-G.L.; project administration, I.-G.L.; funding acquisition, I.-G.L. All authors have read and agreed to the published version of the manuscript.

Funding: This work was supported by the National Research Council of Science \& Technology (NST) grant by the Korean government (MSIP) (No. CAP-16-05-KIMM) and by the National Research Foundation of Korea (NRF) grant by the Ministry of Science and ICT (No. NRF-2018K1A3A1A61024274).

Institutional Review Board Statement: Not applicable.

Informed Consent Statement: Not applicable.

Data Availability Statement: Not applicable.

Acknowledgments: This work was supported by the National Research Council of Science \& Technology (NST) grant by the Korean government (MSIP) (No. CAP-16-05-KIMM) and by the Global Infrastructure Program through the National Research Foundation of Korea (NRF) funded by the Ministry of Science and ICT (No. NRF-2018K1A3A1A61024274).

Conflicts of Interest: The authors declare that they have no known competing financial interests or personal relationships that could have appeared to influence the work reported in this paper.

\section{References}

1. Muigai, H.H.; Choudhury, B.J.; Kalita, P.; Moholkar, V.S. Physico-chemical characterization and pyrolysis kinetics of Eichhornia Crassipes, Thevetia Peruviana, and Saccharum Officinarum. Fuel 2021, 289, 119949. [CrossRef]

2. Magalhaes, D.; Gurel, K.; Matsakas, L.; Christakopoulos, P.; Pisano, I.; Leahy, J.J.; Kazanc, F.; Trubetskaya, A. Prediction of yields and composition of char from fast pyrolysis of commercial lignocellulosic materials, organosolv fractionated and torrefied olive stones. Fuel 2021, 289, 119862. [CrossRef]

3. Brindhadevi, K.; Anto, S.; Rene, E.R.; Sekar, M.; Mathimani, T.; Chi, N.T.L.; Pugazhendhi, A. Effect of reaction temperature on the conversion of algal biomass to bio-oil and biochar through pyrolysis and hydrothermal liquefaction. Fuel 2021, 285, 119106. [CrossRef]

4. Choi, Y.S.; Choi, S.K.; Kim, S.J.; Jeong, Y.W.; Soysa, R.; Rahman, T. Fast pyrolysis of coffee ground in a tilted-slide reactor and characteristics of biocrude oil. Environ. Prog. Sustain. Energy 2017, 36, 655-661. [CrossRef]

5. Zhang, X.; Zhang, Q.; Wang, T.; Li, B.; Xu, Y.; Ma, L. Efficient upgrading process for production of low quality fuel from bio-oil. Fuel 2016, 179, 312-321. [CrossRef]

6. Zhang, Q.; Xu, Y.; Li, Y.; Wang, T.; Zhang, Q.; Ma, L.; He, M.; Li, K. Investigation on the esterification by using supercritical ethanol for bio-oil upgrading. Appl. Energy 2015, 160, 633-640. [CrossRef]

7. Prajitno, H.; Insyani, R.; Park, J.; Ryu, C.; Kim, J. Non-catalytic upgrading of fast pyrolysis bio-oil in supercritical ethanol and combustion behavior of the upgraded oil. Appl. Energy 2016, 172, 12-22. [CrossRef]

8. Gollakota, A.R.K.; Reddy, M.; Subramanyam, M.D.; Kishore, N. A review on the upgradation techniques of pyrolysis oil. Renew. Sust. Energ. Rev. 2016, 58, 1543-1568. [CrossRef]

9. Bharath, G.; Rambabu, K.; Hai, A.; Banat, F.; Taher, H.; Schmidt, J.E.; Show, P.L. Catalytic hydrodeoxygenation of biomass-derived pyrolysis oil over alloyed bimetallic $\mathrm{Ni}_{3} \mathrm{Fe}$ nanocatalyst for high-grade biofuel production. Energy Convers. Manag. 2020, 213, 112859. [CrossRef]

10. Lee, J.H.; Lee, I.G.; Jeon, W.; Ha, J.H.; Lee, K.Y. Catalytic upgrading of bio-tar over a MgNiMo/activated charcoal catalyst under supercritical ethanol conditions. Catal. Today 2018, 316, 237-243. [CrossRef]

11. Ahmadi, S.; Yuan, Z.; Rohani, S.; Xu, C. Effects of nano-structured CoMo Catalysts on hydrodeoxygenation of fast pyrolysis oil in supercritical ethanol. Catal. Today 2016, 269, 182-194. [CrossRef]

12. Cheng, S.; Wei, L.; Julson, J.; Muthukumarappan, K.; Kharel, P.R. Upgrading pyrolysis bio-oil to biofuel over bifunctional Co-Zn/HZSM-5 catalyst in supercritical methanol. Energy Convers. Manag. 2017, 147, 19-28. [CrossRef]

13. Isa, K.M.; Snape, C.E.; Uguna, C.; Meredith, W.; Deng, H. Pyrolysis oil upgrading in high conversions using sub- and supercritical water above $400{ }^{\circ} \mathrm{C}$. J. Anal. Appl. Pyrol. 2016, 119, 180-188. [CrossRef]

14. Li, W.; Xie, X.A.; Tang, C.Z.; Li, Y.; Li, L.; Wang, Y.L.; Fan, D.; Wei, X. The distribution of bio-oil components with the effects of sub/supercritical ethanol and free radicals during cellulose liquefaction. BioResources 2016, 11, 9771-9778. [CrossRef]

15. Li, W.; Xie, X.A.; Tang, C.Z.; Li, Y.; Li, L.; Wang, Y.L.; Wei, X.; Fan, D. Effects of hydroxyl and hydrogen free radicals on the liquefaction of cellulose in sub/supercritical ethanol. J. Fuel Chem. Technol. 2016, 44, 415-421. [CrossRef]

16. Primaz, C.T.; Schena, T.; Lazzari, E.; Caramao, E.B.; Jacques, R.A. Influence of the temperature in the yield and composition of the bio-oil from the pyrolysis of spent coffee grounds: Characterization by comprehensive two dimensional gas chromatography. Fuel 2018, 232, 572-580. [CrossRef]

17. Ravindran, R.; Jaiswal, S.; Abu-Ghannam, N.; Jaiswal, A.K. Two-step sequential pretreatment for the enhanced enzymatic hydrolysis of coffee spent waste. Bioresour. Technol. 2017, 239, 276-284. [CrossRef] 
18. Goh, B.H.H.; Ong, H.C.; Chong, C.T.; Chen, W.H.; Leong, K.Y.; Tan, S.X.; Lee, X.J. Ultrasonic assisted oil extraction and biodiesel synthesis of spent coffee ground. Fuel 2020, 261, 116121. [CrossRef]

19. Sarno, M.; Iuliano, M. Active biocatalyst for biodiesel production from spent coffee ground. Bioresour. Technol. 2018, 266, 431-438. [CrossRef]

20. Zhang, Y.; Ji, G.; Ma, D.; Chen, C.; Wang, Y.; Wang, W.; Li, A. 2020. Exergy and energy analysis of pyrolysis of plastic wastes in rotary kiln with heat carrier. Process Saf. Environ. Protect. 2020, 142, 203-211. [CrossRef]

21. Suriapparao, D.V.; Yerrayya, A.; Nagababu, G.; Guduru, R.K.; Kumar, T.H. Recovery of renewable aromatic and aliphatic hydrocarbon resources from microwave pyrolysis/co-pyrolysis of agro-residues and plastic wastes. Bioresour. Technol. 2020, 318, 124277. [CrossRef] [PubMed]

22. Lee, D.; Nam, H.; Wang, S.; Kim, H.; Kim, J.H.; Won, Y.; Hwang, B.W.; Kim, Y.D.; Nam, H.; Lee, K.H.; Ryu, H.J. Characteristics of fractionated drop-in liquid fuel of plastic wastes from a commercial pyrolysis plant. Waste Manag. 2021, 126, 411-422. [CrossRef] [PubMed]

23. Park, J.Y.; Jeon, W.J.; Lee, J.H.; Nam, B.; Lee, I.G. Effects of supercritical fluids in catalytic upgrading of biomass pyrolysis oil. Chem. Eng. J. 2019, 377, 120312. [CrossRef]

24. Somnuk, K.; Eawlex, P.; Prateepchaikul, G. Optimization of coffee oi extraction from spent coffee grounds using four solvents and prototype-scale extraction using circulation process. Agric. Nat. Resour. 2017, 51, 181-189.

25. Fischer, A.; Du, S.; Valla, J.A.; Bollas, G.M. The effect of temperature, heating rate, and ZSM-5 catalyst on the product selectivity of the fast pyrolysis of spent coffee grounds. RSC Adv. 2015, 5, 29252-29261. [CrossRef]

26. Bok, J.P.; Choi, H.S.; Choi, Y.S.; Park, H.C.; Kim, S.J. Fast pyrolysis of coffee grounds: Characteristics of product yields and biocrude oil quality. Energy 2012, 47, 17-24. [CrossRef]

27. Farobie, O.; Matsumura, Y. Biodiesel production in supercritical methanol using a novel spiral reactor. Procedia Environ. Sci. 2015, 28, 204-213. [CrossRef]

28. Akkarawatkhoosith, N.; Kaewchada, A.; Jaree, A. Production of biodiesel from palm oil under supercritical ethanol in the presence of ethyl acetate. Energy Fuels 2019, 33, 5322-5331. [CrossRef]

29. Iisa, K.; Robichaud, D.J.; Watson, M.J.; Dam, J.T.; Dutta, A.; Mukarakate, C.; Kim, S.; Nimlos, M.R.; Baldwin, R.M. Improving biomass pyrolysis economics by integrating vapor and liquid phase upgrading. Green Chem. 2018, 20, 567-582. [CrossRef]

30. Uzoejinwa, B.B.; He, X.; Wang, S.; Abomohra, A.E.F.; Hu, Y.; Wang, Q. Co-pyrolysis of biomass and waste plastics as a thermochemical conversion technology for high-grade biofuel production: Recent progress and future directions elsewhere worldwide. Energy Convers. Manag. 2018, 163, 468-492. [CrossRef]

31. Kim, Y.M.; Jae, J.; Kim, B.S.; Hong, Y.; Jung, S.C.; Park, Y.K. Catalytic co-pyrolysis of torrefied yellow poplar and high-density polyethylene using microporous HZSM-5 and mesoporous Al-MCM-41 catalysts. Energy Convers. Manag. 2017, 149, 966-973. [CrossRef]

32. Lin, X.; Lei, H.; Huo, E.; Qian, M.; Mateo, W.; Zhang, Q.; Zhao, Y.; Wang, C.; Villota, E. Enhancing jet fuel range hydrocarbons production from catalystic co-pyrolysis of Douglas fir and low-density polyethylene over bifunctional activated carbon catalysts. Energy Convers. Manag. 2020, 211, 112757. [CrossRef]

33. Jeon, M.J.; Choi, S.J.; Yoo, K.S.; Ryu, C.; Park, S.H.; Lee, J.M.; Jeon, J.K.; Park, Y.K.; Kim, S. Copyrolysis of block polypropylene with waste wood chip. Korean J. Chem. Eng. 2011, 28, 497-501. [CrossRef]

34. Chen, W.; Shi, S.; Chen, M.; Zhou, Z. Fast co-pyrolysis of waster newspaper with high-density polyethylene for high yields of alcohols and hydrocarbons. Waste Manag. 2017, 67, 155-162. [CrossRef]

35. Zanella, E.; Zassa, M.D.; Navarini, L.; Canu, P. Low-temperature co-pyrolysis of polypropylene and coffee wastes to fuels. Energy Fuels 2013, 27, 1357-1364. [CrossRef]

36. Hu, M.; Laghari, M.; Cui, B.; Xiao, B.; Zhang, B.; Guo, D. Catalytic cracking of biomass tar over char supported nickel catalyst. Energy 2018, 145, 228-237. [CrossRef]

37. Kanak, M.A.A.; Park, J.Y.; Lee, I.G. Catalytic cracking of oleic acid over zeolites. Key Eng. Mater. 2019, 814, 517-521. [CrossRef]

38. Twaiq, F.A.; Mohamed, A.R.; Bhatia, S. Liquid hydrocarbon fuels from palm oil by catalytic cracking over aluminosilicate mesoporous catalysts with various Si/Al ratios. Microporous Mesoporous Mat. 2003, 64, 95-107. [CrossRef]

39. Hu, W.; Wang, H.; Lin, H.; Zheng, Y.; Ng, S.; Shi, M.; Zhao, Y.; Xu, R. Catalytic decomposition of oleic acid to fuels and chemicals: Roles of catalyst acidity and basicity on product distribution and reaction pathways. Catalysts 2019, 9, 1063. [CrossRef]

40. Mancio, A.A.; da Costa, K.M.B.; Ferreira, C.C.; Santos, M.C.; Lhamas, D.E.L.; da Mota, S.A.P.; Leao, R.A.C.; de Souza, R.O.M.A.; Araujo, M.E.; Borges, L.E.P.; et al. Thermal catalytic cracking of crude palm oil at pilot scale: Effect of the percentage of $\mathrm{Na}_{2} \mathrm{CO}_{3}$ on the quality of biofuels. Ind. Crop. Prod. 2016, 91, 32-43. [CrossRef]

41. Twaiq, F.A.; Zabidi, N.A.M.; Bhatia, S. Catalytic conversion of palm oil to hydrocarbons: Performance of various zeolite catalysts. Ind. Eng. Chem. Res. 1999, 38, 3230-3237. [CrossRef] 